\title{
Improvement of the Quality of Engineering Education Based on Modern Pedagogical Approaches
}

\author{
Ekaterina Babeshko \\ Moscow State University of Civil Engineering \\ (National Research University), \\ Russian Federation, Moscow \\ katerina_as@mail.ru
}

\begin{abstract}
The article is dedicated to the problem of improvement of the quality of engineering education. The analysis of scientific research has established the following: modern pedagogical approaches are not used to a large extent in universities, which does not allow to intensively build the competencies of future engineers. The author has developed suggestions for improving the process of higher education in the context of modern approaches to education. He argues that for the effective training of future engineers in accordance with selected innovative training tools (interactive methods and technologies) and updated content of engineering education with focus on competency-based approach, psychological and pedagogical support (selection of methods and tools) should be selected. Simultaneous formation of multiple competencies can occur in the framework of solving the problem of mastering the unit of educational content through interactive actions using a certain technological method (its content and the content of education define specific competency components).
\end{abstract}

Keywords - innovative technology, interactive technology, quality of engineering education, competency-based approach, psychological and pedagogical tools, psychological and pedagogical support, modern pedagogical approaches in education.

\section{INTRODUCTION}

The production sector, which is in a deep crisis, could not provide jobs for young engineers, which led to a sharp decline in the status value of engineering education and the choice of engineering specialties by school graduates [1].

Russian economy will face the problem of demand for engineering personnel due to the fact that over the past 10-15 years the market labour has changed markedly, and in the coming years the need for new engineering specialties can increase by 4 times $[2,3]$.

The question of the importance of training of engineers was raised at the republican level. The president of the Russian Federation Vladimir Putin in 2012 stated that "Russian vocational education should become competitive at global level. The engineering personnel brought up by Russian universities will be the basis for the modernization of the economy" [4].

The main purpose of engineering education is the need to form the student's conscious desire for self-knowledge, perception of the surrounding world and its problems, productive activities.

In 2018, more specific measures of the President followed: in his message to the Federal Assembly (2018) he set the following task: "We need to quickly upgrade the system vocational education, achieve a qualitative change in the training of the students, especially in the promising areas of technological development."

This means that the future engineer at the university should achieve comprehensive personal development as a complex of humanitarian, socio-economic, natural science and general engineering training. At the same time, he shall have deep specialized knowledge, firmly assimilated skills to perform all required types of professional activities. In addition, the university should increase the level of communication readiness of graduates able to participate in various areas of social life. These requirements are components of the concept of "quality of engineering education, which is understood as integral characteristics of the education system, reflecting the degree of compliance of actually attainable results of education to regulatory requirements, social and personal expectations of students [5].

However, at present, although there is progress in many areas of modernisation of engineering education, not enough attention is paid to modern approaches in the education of students. Modern approaches include, in our understanding, the implementation of pedagogical innovation in teaching. These are all tools being developed or already used to build the competencies of the future engineer (education content, logistics tools - activities to improve the educational process, textbooks, programmes, etc., down to assignments and instructions to students for each competency, each unit of training material and instructions for performing actions to form knowledge and skills within a given training task. The issue of creating conditions to ensure and organize the cognitive activities of students in innovative educational process requires special consideration [6].

The identified contradiction between the accelerating modernisation of the economy, requiring skilled engineering personnel, and Russian vocational education that cannot provide them to the production sector due to the sharp decline in the status value of engineering education and insufficiently 
high level of quality of education of students at universities determined the course of the study.

We believe that competently constructed interaction of the participants in the educational process, which takes into account all the actions of students in accordance with selected pedagogical innovations in teaching, optimizing pedagogical practice and aimed at the implementation of competency-based approach, will contribute to a high-quality training of the future engineer.

\section{PURPOSE AND OBJECTIVES OF THE STUDY}

Purpose of the study: to analyse and summarize the existing best practices for the education of engineers and develop suggestions for the improvement of the university learning process in modern approaches to education.

Tasks:

to conduct a study of the practice of advanced pedagogical experience Russia on the content and training of the future engineer

to analyse the state of the current problem of improvement of the quality of engineering education in Russia;

to identify problems in the education of future engineers, in particular in the framework of modern approaches;

to determine the content of psychological and pedagogical support for the process of training of future engineers.

\section{LITERATURE ANALYSIS}

Leaders, scientists interested in solving the problem suggest ways to dramatically improve the engineering education in country. We will consider as part of our study how it is proposed to improve the quality of education of the future engineer in Russia.

During the study and analysis of scientific and practical publications it was determined that Russian centres of engineering pedagogy accredited by IGIP have been created [6].

RMK IGIP has begun to address strategic, tactical and operational tasks. Among them:

1) ongoing interaction with IGIP International Monitoring Committee;

2) management of the process of formation of the national network of the centres of engineering pedagogy;

3) organisational, informational, and advisory support of CEPs necessary to ensure psychological and pedagogical training and development of the teachers of technical institutions;

4) coordination of the processes of interaction of centres located in different regions of the country; formation of the international register of teachers of technical institutions of Russia [7].

The problem of comparing educational and professional standards is investigated; the authors believe that there is rational balance between the degree of depth of description and documentary support of the educational process through the creation of academic documentation (schedules, evaluation tools, guidelines for the organisation of independent work of students) and the level of expected competence of students. In accordance with the current standard of the International Society for Engineering Pedagogy (IGIP) the teacher of a modern technical institution in addition to professional knowledge in the subject area shall master information and computer technology (ICT) and foreign languages. The project of "Modern Digital Educational Environment in the Russian Federation" prepared regulations, orders and procedures that "allow teachers to intertwine online courses with educational programmes." The importance of the humanitarian disciplines of pedagogical tenor for the effectiveness of mastering engineering disciplines in technical institutions and gaining the necessary competencies for the future graduate, factors determining the formation of individual educational trajectory of a student at a university were determined $[8,9,10]$.

Some researchers believe that the problem of training of engineers can be solved

1 ) in the framework of the model involving the development of valuation tools, the formation of motivation through diagnosis and reflection of their professional activities ("motivation"), the implementation of training of academic staff in advanced training system in accordance with the principles of person oriented and contextual learning ("implementation"), organisation information and methodological support, provision of remote support of professional and pedagogical development of teachers ("support");

2) in the structure of the academic cluster, in which the specificity of the scientific and methodological activity of the teacher of a technical institution is presented, consisting of a set of species requiring the ability to transfer its results to the educational process; this is achieved by the results of research and applied works of the teacher, their systematization and implementation in the content of education using the latest methods and technologies demanded by production [11].

Thus, summarizing the issue of organisational activities of the universities related to the problem of training a qualified engineer, we believe the following:

the problem has taken on a state-wide scale;

researchers have examined the key components of pedagogical approaches to the education of future engineers;

work has begun on all levels of education to update and select pedagogical approaches (from updating the organisation of operation of the universities and their interaction with business entities, development of programmes, curricula taking into account generated competencies, etc.) for the improvement of the education a future engineer;

the pedagogical approaches used in the practice of training future engineers are currently innovative, which is proved by the researchers and entire teams of many technical institutions (MISU, SVFU, UGI, LETI NII TSU, National Mineral Resources Mining University, Siberian Federal University, etc.). 
However, providing education content is not enough. It is also important to organise the interaction of participants in the pedagogical process through student-teacher interaction, so as to ensure the effective comprehensive development of the personality of the future engineer. This means that at the university the student must be ready to obtain aggregate humanitarian, socio-economic, natural science, general engineering knowledge and skills.

In our study, which is limited by the framework of the process of training of future engineers at the university in the framework of modern pedagogical approaches, let us review the following provisions:

1) a system of organisational measures in the operation of universities to ensure the process of education and evaluation of the quality of education of engineers;

2) determination of the content of education of future engineers (what to teach);

3) organisation of the teaching process for the students that study engineering specialties (how to teach?);

4) selection of methods and technologies for more effective training of engineers (with what to teach?).

Our decision to consider the issue within the framework of the above definitions is not unintentional, as these are key characteristics of the organisation and implementation of the teaching process at the university.

Regarding the system of organisational measures in the operation of universities to ensure the process of education and evaluation of the quality of education of engineers, the researchers suggest the following:

1) a powerful state technical propaganda programme of technical achievements, especially in the regions [12];

2) implementation of the project approach in the operation of educational organizations [13];

3) establishment and development of the system of independent assessment of engineering qualifications in relation to fuel and energy complex [14];

4) development of the basic elements of the quality system of the university, the structure of the university model for assessing quality, the direction of the operation of the university in this area, where the management of the quality of training requires formalized procedures (models) for its assessment, implemented in the framework of the ACS of the university, creation of university website as a factor of improvement of the quality of training;

5) a practice-oriented approach that offers ensuring the unity of the educational, scientific and production process (creation of the centre of "Energy-Efficient Building Materials", the main the purpose of which is the scientific and technical support of implementation of innovative technologies in the area of production of energy-efficient building materials);

6) construction of professional experience in designing professional academic disciplines;
7) identification of the comprehensive assessment of the level of formation of competencies, which "can serve as the basis for the mathematical model for determining the generalised rating indicator of training";

8) focus on the modular structure of educational programmes, suggest to divide the curricula of areas and specialties, where disciplines are taught in the basic parts of the cycles having the same name but differing in content.

In determining the educational content of future engineers (what to teach) in engineering the following areas are generally highlighted: technological, design (project), research, organisational. Professionals must possess professional competencies.

In the study of the work of researchers on the organisation and performance of the process of training of students in engineering specialties (how to teach?) we express our agreement with the authors that the main competencies that a graduate of a technical institution should master should be formed during theoretical training, practical training, carrying out research work, in the process of implementation of intersubjective relations between the disciplines of general technical and professional cycles

The choice of a competency-based approach to the content of education in the training of an engineer is not accidental, as it aims to engage teachers and students in innovation; close interaction with the customer, both of the producer and the consumer of innovation. In addition to the competency-based approach, according to the author of the research, and we agree with him, innovative education: design, multidisciplinary, practice oriented, contribute to the formation of personal and professional qualities of an engineer $[15,16]$.

Let us determine how much attention is paid at the Russian universities to the issue of using innovative technologies in the quality training of engineers. The study of materials of the research of the training of future engineers in the framework of innovative technologies allowed determining that they exist. Researchers in their works:

1) offer to implement pair and group interactions using communication between trainees (joint study of the text in a certain algorithm, mutual dictations and discussion of problems);

2) use innovative technology for the solutions of invention tasks of G. S. Altshuller;

3) use interactive technologies through which an interactive learning model can be introduced (work in small groups; business games; lectures with case presentation; heuristic conversation; workshops in form of discussion; conferences; collaboration technology; modelling technology, or project method (as extracurricular activities);

4) for the success of the reform, it is necessary to rely on an adequate psychological pedagogical theory, in which the psychological and pedagogical theory of context education can become the conceptual basis of the education reform. In this case, the university teacher will obtain clear guidelines for making design decisions on the implementation of the reform. 
However, as the practice of Russian education shows, only the selection of methods and technologies and their indication in the programme will not affect the process of formation of competencies of the future engineer. And we express our agreement with the author that "in the conditions a dynamic economy there is a problem of development of theoretical, methodological and practical foundations of pedagogical support."

In the selection of methods and technologies for more effective training of engineers (with what to teach?) it is important to determine how the educational process is provided to the fullest extent, that is, to what extent a certain innovation in teaching is equipped.

In providing students with instructions and guidelines for implementation of actions, the research work of O.S. Zorina is of interest. The author proposed the model as a holistic process of interconnected components of contextual, communicative, personality and activity, humanitarian and anthropological, humanistic, cultural and project approaches. The work of O.S. Zorina is an example and a special case of formation of only one competency - communicative. Moreover, the content of the educational complex is not sufficiently explained, which does not allow to determine which methods and content allows achieving the formation of the communicative competence.

Conclusion: studies to improve the preparation of the future engineer in the context of modern pedagogical approaches subject to psychological pedagogical support, allowing you to organize all stages of student's interactive cognitive activity over the unit of content of education in the formation of competencies, with teacher-student interaction, are virtually non-existent.

\section{CONCLUSIONS AND PROPOSALS}

1) The study and analysis of modern pedagogical approaches in the training of the future engineer allowed making the following conclusions and proposals.

2) There are modern pedagogical approaches that allow a significant improvement of the quality of engineering education in Russia; their implementation depends on many factors that are presented to a fairly large extent in scientific research, documents, etc.

3) Regarding the problem of the development of pedagogical support of training of future engineers, we take the liberty to add psychological support to the pedagogical component. Our guess can be justified by the fact that the content of education should prepare a comprehensively developed individual. Therefore, we cannot do in the teaching process without the use of psychological and pedagogical theory of contextual education, psychological techniques, accounting for personal qualities and achievements of the students forming an individual educational trajectory.

4) Many academic disciplines taught at the university have the potential for the formation of several competencies due not only to content, but also to the processing of the content in an interactive environment cognitive activity. Therefore, we believe that the ensuring of student activities at the level of educational communicative tasks will not affect all other competencies, for which there exist also conditions within the boundaries of interactive technology and educational material on the studied discipline. Let us assume that several competencies can be formed in the conditions of solving the task of mastering a unit of educational content through interactive activities with the use of a certain technological technique (its content and the content of the educational material for the studied discipline highlight specific competency components). Then you need to expand the academic support to the level of psychological and pedagogical support, as a significant number of modern pedagogical approaches will be leveraged. This need is due to the versatility of the content of engineering education to be considered when planning the work in the educational process.

5) One of the essential conditions in the training of future engineers is the teacher. The sufficiency of equipment of interaction of the participants of the learning process (teacherstudent) affects the quality of mastering of the engineering profession by a student. A more rational use of modern approaches in the practice of training of future engineers will require additional work of the teachers, fairly transparent and reflecting the actual actions of the participants in the pedagogical process at the student-teacher level in terms of the organisation of cognitive activity of students over the unit of content of subject education in conjunction with techniques and methods of interactive technologies. Personal and professional competencies of the future engineer, the assimilation of which in our opinion will contribute to better engineering education, should be highlighted as part of the content of the unit of subject education and in the techniques and methods of interactive technologies.

\section{References}

[1] V.M Prikhodko, Z.S. Sazonova, "Engineering pedagogy-the basis of professional training of engineers and scientific and pedagogical personnel" Higher education in Russia. 2014. vol. 4.

[2] T.A. Kornilov, "Engineering and technical Institute NEFU-60 years" Industrial and civil construction. 2016. vol. 8.1

[3] S.G. Antsupova, G.P. Afonskaya, "Problems and future of engineering education" Modernization of engineering education: Russian traditions and modern innovations. Yakutsk. 2017. 311 p.

[4] V.V. Putin, "Election program of the all-Russian political party "United Russia" (at the elections of the President of Russia on March 4, 2012) [Electronic resource]" Vladimir Putin 2012. http://putin2012.ru/program/2.

[5] R.R. Garifullina, "Formation of scientific and methodological competence of technical University teachers in the structure of scientific and educational cluster" Dissertation of candidate of pedagogical Sciences: 13.00.08. Kazan, 2018.

[6] Z.S. Sazonova, "Methodological seminar MADI-IGIP: history and prospects" Higher education in Russia. 2015. vol. 2. pp. 3039.

[7] V.M Prikhodko, L.G. Petrova, A.N. Soloviev, E.I. Makarenko "On the activities Of the Russian monitoring Committee IGIP" Higher education in Russia. 2011. vol. 12. pp. 39-47. 
[8] L.V. Brykova, A.G. Golovchenko, S.A. Smirnova, "Engineering pedagogy and prospects of its application" Man and education. 2015. vol. 4 (45)

[9] V.G. Ivanov, Z.S. Sazonova, M.B. Sapunov, "Engineering pedagogy: an attempt at typology" Higher education in Russia. 2017. - vol. 8/9 (215). pp. 32-42.

[10] V.S. Senashenko, A.A. Verbitsky, G.I. Ibragimov, P.N. Osipov, "Engineering pedagogy: methodological issues (round table)" Higher education in Russia. 2017. vol. 11 (217). pp. 137-157.

[11] M.G. Minin, G.F. Belomestnova, G.F. Benson, V.S. Pakanova, "Pedagogical training of the teacher of engineering University" Higher education in Russia. 2014. vol. 4.

[12] V.P. Solovyov, T.A. Pereskokova, "Formation of social and personal qualities of the engineer" Engineering education. 2019. vol. 25. pp. 119-129.
[13] E.A. Babeshko, "Contextual Education as a Condition for the Development of Professional Qualities of a Manager" International Journal of Applied Exercise Physiology. 2019. T. 8. vol.2.1.pp. 975-980.https://elibrary.ru/item.asp?id=38590173.

[14] V.S. Sheinbaum, "Problems of higher education in the formation and development of the system of independent assessment of engineering qualifications in relation to the fuel and energy sector" Engineering education. 2018. vol. 23. pp. 10-21.

[15] N.G. Miloradova, A.D. Ishkov, "Formation of professional-andpedagogical competence of the technical university teacher" Modem Journal of Language Teaching Methods. 2018. T. 8. vol. 11. pp. 631-639. https://elibrary.ru/item.asp?id=36382908.

[16] O.S. Zorina, "Formation of communicative competence of future engineers" Dissertation of candidate of pedagogical Sciences: 13.00.08. Nizhny Novgorod. 2016. 235 p 